\title{
Plantão psicológico e o cuidado na urgência: panorama de pesquisas e intervenções
}

\author{
Fabio Scorsolini-Comin - Universidade Federal do Triangulo Mineiro, Uberaba, Brasil
}

\begin{abstract}
Resumo
Este estudo de revisão integrativa da literatura científica teve por objetivo conhecer as principais pesquisas e intervenções realizadas na área do plantão psicológico. As buscas foram realizadas nas bases LILACS, SciELO, PePSIC, PsycINFO e na Biblioteca Digital de Teses e Dissertações da Universidade de São Paulo no período de 2000 a 2014. Foram analisadas, na íntegra, 47 produções. O perfil predominante é de estudos qualitativos, empíricos e relatos de experiência desenvolvidos em serviços-escolas de Psicologia, com estudantes, supervisores e pessoas atendidas no plantão, a partir do referencial fenomenológico-existencial. Destaca-se a necessidade de que esses relatos dialoguem com os saberes teóricos da área, bem como sejam incrementados por pesquisas. As práticas podem ser mais diversificadas em termos teóricos e desenvolvidas em comunidades. Palavras-chave: plantão psicológico; aconselhamento psicológico; urgência.
\end{abstract}

\section{Psychological emergency and urgent care: a research and interventions overview}

\begin{abstract}
This article presents an integrative review of the literature on emergency psychological services, highlighting the major research and interventions in this area. Searches were conducted in LILACS, SciELO, PePSIC, PsycINFO and the Digital Library of Theses and Dissertations, University of São Paulo from 2000 to 2014. 47 publications were analyzed in their entirety. The profile is predominantly of qualitative, empirical studies and experience reports developed in School Psychological Services with students, supervisors and persons who are attended in the emergency service, from the phenomenological-existential scope. We emphasize the need of dialogue of these reports with theoretical knowledge in the area as well as enhanced by research. Practices can be more diverse in theory and developed within communities. Keywords: emergence psychological services; psychological counseling; emergency.
\end{abstract}

\section{Guardia psicológica y la atención de urgencia: panorama de las investigaciones e intervenciones}

\begin{abstract}
Resumen
Este estudio de revisión integrada de la literatura científica, tuvo por objetivo conocer las principales investigaciones e intervenciones realizadas en el área de la guardia psicológica. Se realizaron búsquedas en las bases LILACS, SciELO, PePSIC, PsycINFO y en la Biblioteca Digital de Tesis y Disertaciones de la Universidad de San Pablo, en el período 2000-2014. Fueron analizados 47 trabajos en su totalidad. El perfil predominante es de estudios cualitativos, empíricos y de informes de experiencia desarrollados en Servicios Psicológicos Escolares, con estudiantes, supervisores y personas atendidas en la guardia, a partir de la teoría fenomenológica existencial. Se destaca la necesidad de diálogo de estos informes con los conocimientos teóricos desarrollados en el área, así como incrementar la investigación. Las prácticas en teoría pueden ser más diversas y desarrolladas en comunidades. Palabras-clave: guardia psicológica; asesoramiento psicológico; urgencia.
\end{abstract}

Embora existam algumas definições possíveis acerca do plantão psicológico e o modo como operacionalizá-lo e pesquisá-lo, a depender do contorno teórico que se adota, é importante mencionar que sua origem data da primeira década do reconhecimento da profissão de psicólogo no Brasil, constituindo uma das práticas mais conhecidas e relatadas em nosso contexto, notadamente nos serviços-escola de Psicologia que aliam ensino, pesquisa e extensão à comunidade. A proposta do plantão psicológico se iniciou em 1969 no Instituto de Psicologia da Universidade de São Paulo, inspirada no modelo norte-americano de atendimento imediato à comunidade intitulado walk in clinics, e constitui uma prática reconhecida pelo Conselho Federal de Psicologia (Mozena, 2009; Rosenberg, 1987). Mesmo sendo uma prática existente há mais de 40 anos no contexto brasileiro, a produção científica na área não acompanha a velocidade dos incrementos propostos nessa modalidade de atendimento e em suas diferentes ofertas em universidades, instituições e comunidades, que revelam novas possibilidades de oferta de apoio psicológico em situações de urgência (Rebouças \& Dutra, 2010).

Segundo Mahfoud (2012), o atendimento psicológico na oferta de plantão pressupõe a necessidade de manter profissionais de Psicologia (ou plantonistas ou estagiários sob supervisão de um profissional) à disposição de uma dada comunidade ou instituição por períodos determinados ou ininterruptos. Esse atendimento pode ser em um único encontro ou desdobrar-se em outros, a depender da necessidade da pessoa que busca ajuda. O que define o plantão é a não delimitação ou sistematização dessa oferta de ajuda, de modo que o profissional esteja disponível para "encontrar 
com o outro na urgência" (Doescher \& Henriques, 2012), oferecendo-lhe suporte emocional, espaço para a expressão de sentimentos e angústias, bem como possibilidade de reorganização psíquica e de instilação de esperança.

Segundo Tassinari (2003), o encontro no plantão tem como pressuposto que a pessoa que busca ajuda possa compreender melhor a sua problemática e sua situação imediata, sendo que o profissional de Psicologia deve estar disponível para explorar possibilidades de resolução do problema sempre com uma atitude de interesse pelo relato e de modo aberto à escuta, em uma consideração positiva pelo outro e pelo que lhe é relatado. O cuidado prestado na urgência pode se dar em forma de acolhimento, compreensão da queixa, de fornecimento de informações e, também, como espaço de escuta e de ressignificação de posturas. Posteriormente, pode ocorrer o encaminhamento dessa pessoa para outros serviços e especialidades.

Há diferentes perspectivas teóricas e metodológicas acerca de como deve ser operacionalizado o atendimento em plantão psicológico, embora predomine, no Brasil, as abordagens humanistas e fenomenológico-existenciais, fruto da tradição da implantação dos primeiros serviços de plantão por parte das universidades e voltados à comunidade (Souza \& Souza, 2011). Ainda assim, as práticas existentes não se mostram homogêneas e envolvem diferentes aspectos, como a própria vinculação desses atendimentos a situações de pesquisa e produção do conhecimento na área (Mahfoud, 2013). É mister compreender não apenas de que modo a prática do plantão psicológico tem ocorrido na contemporaneidade, como também a pesquisa nessa importante área relacionada ao aconselhamento psicológico (Scorsolini-Comin \& Santos, 2013).

Souza e Souza (2011) analisaram a produção da pós-graduação brasileira na área do plantão psicológico em termos das teses e dissertações defendidas entre 1997 e 2009. O perfil encontrado foi de dissertações de mestrado defendidas em programas de pós-graduação da região sudeste e desenvolvidas segundo a abordagem centrada na pessoa. No entanto, o recorte desse estudo não incluiu entre as evidências a produção científica veiculada em artigos científicos, desconsiderando um amplo campo de divulgação da pesquisa acadêmica. A partir desse breve panorama apresentado, este estudo teve por objetivo conhecer as principais pesquisas e intervenções realizadas na área do plantão psicológico na atualidade, por meio de uma revisão integrativa da literatura científica.

\section{Método}

\section{Tipo de estudo}

Trata-se de uma revisão integrativa da literatura científica, que tem como objetivo não apenas mapear a produção acerca de determinado assunto, mas também discuti-la de modo integrado e crítico, a fim de possibilitar o levantamento de lacunas e de evidências para a prática profissional na área. Os procedimentos adotados nesta revisão seguem a proposta de Mendes, Silveira e Galvão (2008): (1) identificação do tema e da questão norteadora; (2) estabelecimento de critérios de inclusão/exclusão; (3) categorização dos estudos; (4) avaliação dos estudos; (5) interpretação dos resultados; (6) síntese do conhecimento. A seleção e a categorização dos estudos foram realizadas por dois juízes independentes. A questão norteadora deste estudo foi: quais as principais pesquisas e intervenções realizadas na área do plantão psicológico?

\section{Bases indexadoras e unitermos empregados}

As buscas pelos artigos indexados foram realizadas nas bases eletrônicas LILACS, SciELO, PePSIC e PsycINFO. A escolha dessas bases deu-se pelo fato de recuperarem boa parte da produção científica nacional e internacional. As buscas pelas teses e dissertações foram realizadas na Biblioteca Digital de Teses e Dissertações da Universidade de São Paulo, criada em 2001 para disponibilizar o conhecimento produzido pelas dissertações de mestrado, teses de doutorado e de livre docência defendidas na Universidade de São Paulo, de modo a permitir que as comunidades brasileira e internacional tenham acesso irrestrito à versão digital completa desses materiais. Essa biblioteca está associada à Networked Digital Library of Theses and Dissertations (NDLTD), o que lhe garante confiabilidade e abrangência. A escolha da biblioteca da USP deve-se ao fato de esta disponibilizar os textos completos de teses e dissertações, bem como pela criação nessa universidade, em 1969, do primeiro serviço de plantão psicológico no Brasil. Desde então, toda uma tradição em pesquisa na área foi criada no Instituto de Psicologia da USP (Mahfoud, 2013; Rosenberg, 1987), o que justifica a escolha dessa base como fonte de evidências para a prática. Em todas essas buscas, foram utilizados os unitermos "plantão psicológico", "psychological emergency attendance", "emergency psychological", que deveriam estar presentes em pelo menos um dos seguintes campos de busca: título, resumo, assunto ou palavra-chave. A seleção desses campos ocorreu pela possibilidade de 
conduzirem a estudos mais diretamente relacionados ao plantão psicológico, desconsiderando estudos que apenas mencionavam a modalidade de atendimento, sem investigá-la.

\section{Critérios de inclusão e de exclusão}

Foram incluídos: (a) estudos que tratassem diretamente do plantão psicológico, em termos de pesquisa e/ou intervenção; (b) artigos indexados acerca do tema, sem restrição do idioma de publicação, tipo de estudo, referencial teórico ou delineamento metodológico, veiculados entre 2000 e 2014; (c) teses de doutorado, teses de livre docência e dissertações de mestrado acerca do tema, publicadas em português, sem restrição de data de publicação, e disponíveis na Biblioteca Digital de Teses e Dissertações da Universidade de São Paulo.

Foram excluídos: (a) materiais como monografias de conclusão de curso, livros, capítulos de livros, resenhas, obituários, editoriais e resumos em anais de congressos; (b) artigos indexados publicados antes do ano 2000; (c) teses e dissertações que não estavam catalogadas na Biblioteca Digital de Teses e Dissertações da Universidade de São Paulo; (d) artigos, teses e dissertações que se distanciassem do tema da revisão ou que apenas mencionavam o plantão psicológico como uma modalidade de atendimento, sem tratar dessa intervenção em seus objetivos ou resultados.

\section{Procedimento}

\section{Coleta de dados}

Os levantamentos foram realizados em um único dia, em dezembro de 2014. Os unitermos e suas combinações foram utilizados nas bases LILACS, SciELO e PePSIC a partir do acesso via BVS-Psi e, posteriormente, na PsycINFO. Os levantamentos iniciais obtidos pela aplicação dos unitermos e suas combinações nessas bases eletrônicas levaram a um montante de artigos que foram lidos e analisados em termos dos critérios de inclusão e de exclusão adotados. Após a aplicação desses critérios, procedimento este realizado por dois juízes independentes, ambos com formação em Psicologia e com treinamento e familiaridade com o tema e os procedimentos da revisão, foram recuperados e analisados na íntegra apenas os artigos que compuseram o corpus do estudo. Os artigos repetidos foram contabilizados apenas uma vez. Em relação às teses e dissertações, as buscas foram realizadas na Biblioteca Digital de Teses e Dissertações da Universidade de São Paulo em um único dia. As teses e dissertações condizentes com os critérios de inclusão e de exclusão adotados, analisadas, também, por dois juízes independentes, foram recuperadas na íntegra via download na base de dados, sendo lidas e analisadas em profundidade para integrarem o corpus do estudo.

\section{Análise dos dados}

Os artigos, teses e dissertações recuperados foram catalogados em uma planilha de Excel para posterior análise. Nessa planilha, foram categorizados em termos de: título, autores, instituição de origem dos autores, ano de publicação, periódico, programa de pós-graduação, tipo de estudo, amostra, instrumentos, objetivo, principais resultados e principais conclusões. Essas categorias foram sistematizadas e organizadas em eixos temáticos, a fim de se construir um perfil das publicações acerca do plantão psicológico. A análise dos dados ocorreu a partir dessas categorias, explorando tanto o perfil das produções, como suas aproximações e distanciamentos. O corpus foi lido e analisado na íntegra e, a partir dos conteúdos abordados em cada produção, bem como das características desses estudos, foram construídos os seguintes eixos temáticos para melhor organização dos achados presentes neste corpo de literatura: (a) o plantão psicológico e sua prática nas universidades; (b) autores e instituições de pesquisa em plantão psicológico; (c) a produção científica na pós-graduação; (d) diálogo com a produção internacional.

\section{Resultados e Discussão}

As buscas iniciais conduziram ao seguinte resultado em termos da quantidade de materiais registrados: SciELO $(n=63)$, PePSIC $(n=18)$, LILACS $(n=25)$, PsycINFO $(n=20)$ e Biblioteca Digital de Teses e Dissertações da Universidade de São Paulo $(n=9)$, totalizando 135 registros. A maior parte dos artigos excluídos tratava de serviços de emergência ou de profissionais que atuam nesses serviços, sem mencionar ou destacar a atuação da Psicologia nesse contexto ou, especificamente, o plantão psicológico. Nas bases latino-americanas, a maior causa de exclusão foi a repetição de artigos entre as três bases. Após a aplicação dos critérios de inclusão e de exclusão, da leitura na íntegra dos estudos e da exclusão dos artigos repetidos, foram recuperados 38 artigos, seis dissertações de mestrado e três teses de doutorado. Esses materiais compuseram o corpus $(N=47)$ do presente estudo de revisão, que corresponde a $34,81 \%$ dos estudos encontrados nas buscas. 


\section{O plantão psicológico e sua prática nas universidades}

Em termos do perfil das publicações, sumarizada na Tabela 1, a maior parte é composta por estudos empíricos e de caso $(n=23 ; 48,93 \%)$, seguida por relatos de experiências profissionais $(n=13 ; 27,65 \%)$, o que destaca a forte ligação do campo do plantão psicológico com a prática profissional. Trata-se, portanto, de um conhecimento essencialmente aplicado. São pesquisas que apresentam programas de estágio em plantão psicológico, experiências com plantonistas, supervisores e com pessoas atendidas nessa modalidade. Esses relatos visam divulgar práticas consideradas bem-sucedidas ou de impacto na área, a fim de que possam contribuir com novas propostas de atendimento. Alguns relatos, no entanto, não se aprofundam em pressupostos teóricos do plantão psicológico, mas na apresentação de programas de estágio, o que tornam os estudos ilustrativos e informativos, importantes para a construção de outros programas de intervenção, mas com limitado poder de reflexão para a prática e a pesquisa na área (Furigo et al., 2009; Gomes, 2008; Mota \& Goto, 2009). A formação profissional é destacada na maioria desses estudos, que apresenta o plantão como possibilidade de aplicação dos conhecimentos psicológicos e como formação técnica considerada não tradicional, em uma perspectiva de clínica ampliada e fortemente ligada a instituições e à comunidade.
Ainda acerca da formação do psicólogo, muitos estudos destacam a importância dos serviços-escolas presentes nas universidades brasileiras como porta de entrada para o atendimento institucional e como formação de recursos humanos para a prática do plantão psicológico e dos serviços de pronto-atendimento (Furigo et al., 2009; Paparelli \& Nogueira-Martins, 2007; Peres, Santos, \& Coelho, 2004). Discutindo a formação dos plantonistas, Schmidt (2012) destaca as entrevistas de plantão como "espaço e tempo de mediação e trânsito de identidades e diferenças, inclusões e exclusões, passado e presente, interior e exterior, na medida em que procuram transpor a proteção do psicodiagnóstico e da triagem, expondo-se à plasticidade dos encontros" (p. 17).

A construção da identidade do psicólogo, ou o "tornar-se psicólogo" (Scorsolini-Comin, Souza, \& Santos, 2008), passa a se dar a partir do encontro com a urgência e o inesperado, de modo a mobilizar, nos estudantes, a adoção de estratégias e a recuperação de recursos teóricos e pessoais para a oferta de uma ajuda pontual que tem como objetivo acolher a demanda, organizá-la e promover uma situação de maior conforto emocional (Chaves \& Henriques, 2008). Nesse processo de estágio, o estudante começaria a construir a sua identidade como futuro psicólogo, estando aberto aos movimentos de permanência e ruptura que constituem o ser profissional. O plantão, nesse sentido,

Tabela 1. Classificação dos Estudos Recuperados em Termos das Ocorrências mais Frequentes nas Diferentes Categorias (N=47)

\begin{tabular}{lll}
\hline \multirow{2}{*}{ Categorias } & $\begin{array}{l}\text { Características, frequências absolutas na amostra e } \\
\text { porcentagens }\end{array}$ & Exemplos na amostra \\
\hline $\begin{array}{l}\text { Instituição de origem do } \\
\text { primeiro autor }\end{array}$ & $\begin{array}{l}\text { Universidade de São Paulo }(n=16 ; 34,04 \%) \\
\text { PUC Campinas }(n=3 ; 6,38 \%)\end{array}$ & $\begin{array}{l}\text { Weintraub (2011) } \\
\text { Perches e Cury (2013) }\end{array}$ \\
& Universidade Federal do Pará $(n=3 ; 6,38 \%)$ & Vieira e Boris (2012) \\
Tipo de estudo & Empírico, estudo de caso $(n=23 ; 48,93 \%)$ & Campos e Cury (2009) \\
& Relato de experiência profissional $(n=13 ; 27,65 \%)$ & Gomes (2008) \\
& Teórico, revisão $(n=11 ; 23,40 \%)$ & Yehia (2004) \\
Amostra & Clientes de serviço-escola $(n=8 ; 17,02 \%)$ & Doescher e Henriques (2012) \\
& Pessoas adoecidas $(n=6 ; 12,76 \%)$ & Kovács et al. (2001) \\
& Estudantes $(n=5 ; 10,63 \%)$ & Paparelli e Nogueira-Martins (2007) \\
Local de coleta & Serviços-escola e universidades $(n=13 ; 27,65 \%)$ & Chaves e Henriques (2008) \\
& Delegacias, presídios, comunidades $(n=11 ; 23,40 \%)$ & Braga, Mosqueira e Morato (2012) \\
& Hospitais, centros de saúde $(n=6 ; 12,76 \%)$ & Cautella Junior (2012) \\
Referencial, perspectiva & Fenomenológico-existencial $(n=18 ; 38,29 \%)$ & Cautella Junior (2012) \\
teórica & Abordagem centrada na pessoa $(n=12 ; 25,53 \%)$ & Scorsolini-Comin (2014a) \\
\hline
\end{tabular}


forneceria condições para essa construção, justamente por permitir ao aluno entrar em contato com eventos e situações, inclusive nas supervisões clínicas, potencialmente transformadoras e em contraposição a um saber cristalizado acerca da prática psicológica.

A formação do estudante de Psicologia é referida na maior parte dos estudos, o que está diretamente relacionado à característica dos trabalhos recuperados, ou seja, de estudos empíricos realizados com estudantes e de relatos de experiências profissionais desenvolvidas em estágios curriculares. Essa formação é pensada em termos de sua relação com os saberes e fazeres do plantão psicológico, de modo que essa prática é considerada fundamental para a construção constante da identidade do psicólogo ou, em outras palavras, a experimentação "de um estilo próprio ou do apoderamento de um saber-fazer profissional" (Schmidt, 2012). Rebouças e Dutra (2010) compreendem o plantão psicológico como uma prática da contemporaneidade, de modo que o estagiário de Psicologia deve estar alinhado às necessidades de intervenções psicológicas que possam aplacar o sofrimento psicológico em situações de urgência, repensando a clínica em uma perspectiva ampliada e fortemente relacionada à dimensão social (Dutra, 2008; Mota \& Goto, 2009; Scorsolini-Comin, 2014a).

Diferentes estudos possuem os serviços-escolas como cenários de pesquisa e intervenção, de modo que as universidades continuam a ser as instituições nas quais o plantão psicológico mais encontra abertura e campo fértil para o desenvolvimento de suas práticas. Entre as modalidades de atendimento mais executadas nos serviços-escolas de Psicologia, o plantão psicológico desponta como uma das principais intervenções realizadas, tanto devido aos bons resultados atingidos em atendimentos anteriores como pela possibilidade de atenção a um grande contingente de pessoas em sofrimento ou que demandam um acolhimento de urgência (Amaral et al., 2012; Gomes, 2008). Embora esse movimento tenha permitido a perpetuação dessa prática profissional, bem como seu ensino, difusão e supervisão, há que se destacar a necessidade de que os atendimentos sejam desenvolvidos também em outras instituições e comunidades (Aun et al., 2006; Braga, Mosqueira, \& Morato, 2012; Mota \& Goto, 2009), a exemplo dos estudos em hospitais universitários, serviços de saúde mental, de cuidados paliativos, de apoio jurídico, escolas, creches, penitenciárias e comunidades religiosas (Bezerra, 2014; Campos \& Cury, 2009; Cautella Junior, 2012; Coin-Carvalho \& Ostronoff, 2014; Knotek, 2006; Kovács, 2010; Perches \& Cury, 2013;
Rocha, 2006; Scorsolini-Comin, 2014b). A diversidade de cenários possibilita a emergência de novas formas de atenção psicológica, sendo o plantão uma modalidade suficientemente flexível e, portanto, passível de aplicação e desenvolvimento (Scorsolini-Comin, 2014a).

Nos relatos de experiências realizadas em serviços-escolas de Psicologia, os estágios (básicos e curriculares, obrigatórios para a formação do psicólogo) não aparecem, necessariamente, associados a uma disciplina de formação no campo do aconselhamento psicológico ou do plantão psicológico ou, ainda, como uma disciplina-estágio (que poderia garantir, a princípio, uma formação teórica na área). Essa característica pode significar que o plantão psicológico constitui uma modalidade de atendimento difundida e ensinada nas universidades de modo aplicado, a partir das experiências em estágios, o que coloca em xeque a transmissão dos conhecimentos teóricos acerca do campo. Ainda que os estágios possuam conteúdos teóricos dos quais os alunos devam se apropriar, observa-se que o plantão se apresenta ao psicólogo em formação como um campo essencialmente de prática, vivencial, o que pode relegar a um plano de menor destaque à pesquisa científica a respeito do tema. Nos estudos recuperados, raras são as menções a núcleos de pesquisa ou laboratórios sobre o assunto, em contraposição à descrição de serviços. Ao considerar a forte presença do plantão psicológico em instituições de ensino, pode-se aventar que os relatos de experiências ainda são pouco frequentes.

Esse movimento pode contribuir para explicar a quantidade reduzida de estudos na pós-graduação $(n=9)$ encontrada na presente revisão e ligada a um único programa de pós-graduação da Universidade de São Paulo. Embora a análise recaia na pós-graduação de apenas uma universidade, como afirmado anteriormente, trata-se da instituição responsável pela maioria dos estudos sobre plantão psicológico recuperados nesta revisão, mesmo desconsiderando as teses e dissertações, de modo que não se trata de um retrato particular, mas de um cenário de evidências para a prática do plantão psicológico. A pesquisa científica deve constantemente aliar-se a essa prática, a fim de que experiências possam ser relatadas (Doescher \& Henriques, 2012; Mota \& Goto, 2009), mas que também pressupostos do plantão psicológico possam subsidiar novas investigações e intervenções em situações de urgência.

\section{Autores e instituições de pesquisa em plantão psicológico}

Sobre o idioma de publicação, quatro artigos foram redigidos em inglês, um em francês e $42 \mathrm{em}$ 
português. Esse dado pode revelar a prática do plantão como algo mais presente no contexto brasileiro, o que também abre a necessidade de compreender outros modelos de atendimento à urgência psicológica existentes no exterior e que, porventura, diferenciem-se das propostas aqui empregadas. Em termos do ano de publicação, a maioria se concentrou no ano de 2012 $(n=8 ; 17,02 \%)$. A maioria dos estudos, resgatada no período de 2000 a 2014, concentra-se no intervalo entre 2006 e 2012 ( $n=37 ; 78,72 \%$ ), o que mostra que se trata de uma produção recente e atualizada, com bastante abertura dos periódicos científicos brasileiros para essa temática. Tal achado também pode apontar para uma maior valorização do plantão psicológico nos últimos anos, com maior espaço para pesquisas nesse campo de intervenção. Acerca das instituições de origem dos autores (primeiro autor do estudo), a Universidade de São Paulo concentra a maioria das investigações $(n=16$; $34,04 \%)$. Retirando-se as teses $(n=3)$ e dissertações $(n=6)$ desse montante, essa instituição, ainda, é responsável pela maior parte da produção científica sobre o plantão psicológico, seguida pela Pontifícia Universidade Católica de Campinas ( $n=3$ ), Universidade Federal do Pará ( $n=3)$, Universidade Federal do Rio Grande do Norte $(n=2)$, Universidade Estadual Paulista "Júlio de Mesquita Filho" (Assis) $(n=2)$, Universidade Federal do Triângulo Mineiro $(n=2)$, Pontifícia Universidade Católica de Minas Gerais (Poços de Caldas) $(n=2)$ e Universidade Mogi das Cruzes $(n=2)$ (Tabela 1).

Sobre a abordagem teórica dos estudos, a maioria utilizou o referencial fenomenológico-existencial $(n=18 ; 38,29 \%)$ com referências a teóricos como Husserl e Heidegger, seguida pela abordagem centrada na pessoa $(n=12 ; 25,53 \%)$, em referência aos estudos de Carl Rogers, o que já poderia ser antecipado pela prevalência dessa abordagem em livros nacionais (Mahfoud, 2012; Rosenberg, 1987; Tassinari, Cordeiro, \& Durange, 2013) e, também, em consonância com estudo anterior sobre o aconselhamento psicológico, diretamente relacionado ao plantão (Scorsolini-Comin \& Santos, 2013). Em todos os artigos nacionais, são mencionados expoentes no campo do plantão e do aconselhamento psicológico, como Miguel Mahfoud (UFMG), Raquel Léa Rosenberg (USP), Maria Luísa Sandoval Schmidt (USP), Henriette Tognetti Penha Morato (USP) e Vera Engler Cury (PUC-Campinas), embora alguns estudos não se posicionem claramente acerca da abordagem adotada para a condução do plantão (Carmona, 2007; Furigo et al., 2009; Peres, Santos, \& Coelho, 2004). Algumas obras basilares desses autores são destacadas como pontos de referência para a criação dos serviços de plantão psicológico e como as primeiras publicações a respeito dessa modalidade no Brasil. Há que se destacar que Henriette Tognetti Penha Morato figura como a principal autora encontrada na presente revisão $(n=2)$, sendo orientadora de sete das teses e dissertações recuperadas, como discutido no eixo seguinte.

\section{A produção científica na pós-graduação}

Na presente revisão, predominaram as dissertações de mestrado, conclusão apoiada pelo estudo de Souza e Souza (2011). Não foram encontrados registros de um mesmo autor que realizou mestrado e doutorado com pesquisas na área do plantão psicológico. Todas as teses e dissertações são advindas de estudos empíricos realizados em diferentes instituições como serviço-escola de Psicologia, escolas, polícia militar e Fundação Casa. Trata-se de estudos que se posicionam criticamente acerca das realidades que exploram, utilizando o plantão psicológico como recurso não tradicional de ajuda psicológica em contextos institucionais e comunitários. Apesar dos diferentes contextos explorados, partem de um mesmo pressuposto teórico, o que compromete a diversificação dos estudos e suas ramificações para outras investigações na graduação e pós-graduação.

Analisando os estudos decorrentes desses trabalhos, a maioria deles não foi publicada em formato de artigos, mas pode estar presente em formatos como capítulos de livros, por exemplo, como a obra organizada por Morato, Barreto e Nunes (2012). Embora seja reforçado o compromisso público com a divulgação desses resultados em materiais que não as próprias teses e dissertações, é importante mencionar que os periódicos científicos são a fonte de maior acesso à produção acadêmica (por meio de acesso público e gratuito), de modo que constituem um veículo importante e valorizado nos diversos meios científicos. Os 38 artigos que compõem o corpus foram publicados em 22 periódicos, todos avaliados pelo Qualis Periódicos da CAPES na área da Psicologia, no período de referência de 2010/2012. Os periódicos mais frequentes foram: Revista do NUFEN ( $n=5$; Qualis B4 na Psicologia), Estudos de Psicologia (Campinas) ( $n=4$; Qualis A2 na Psicologia), Boletim de Psicologia $(n=3$; Qualis B2 na Psicologia), Estudos e Pesquisas em Psicologia ( $n=3$; Qualis B1 na Psicologia), Psicologia em Estudo $(n=2$; Qualis A2 na Psicologia); Psicologia: Ciência e Profissão ( $n=2$; Qualis A2 na Psicologia) e Imaginário ( $n=2$; Qualis B3 na Psicologia). Apenas três estudos da amostra foram publicados em revistas Qualis A1 na 
Psicologia (Paidéia, Psicologia: Teoria e Pesquisa e Psicologia: Reflexão e Crítica). Embora o critério Qualis da CAPES seja apenas um dos muitos indicadores de produção científica, podendo variar segundo o período de avaliação e os critérios adotados e constantemente aprimorados, esses dados revelam que os estudos sobre plantão psicológico têm encontrado espaço em periódicos com seletiva política editorial, reforçando a qualidade dessas investigações.

Em relação às teses e dissertações, todas foram produzidas no Programa de Pós-graduação em Psicologia Escolar e do Desenvolvimento Humano do Instituto de Psicologia da Universidade de São Paulo. A maioria foi originada no Laboratório de Estudos e Prática em Psicologia Fenomenológica e Existencial (LEFE-IP-USP), sendo a mais antiga datada de 2005, e a mais recente, de 2014. Essas produções foram orientadas por Henriette Tognetti Penha Morato $(n=7)$, Maria Luísa Sandoval Schmidt $(n=1)$ e Eda Marconi Custódio $(n=1)$. Esses achados remontam à história do aconselhamento e do plantão psicológico em nosso país, como enfatizado nos estudos recuperados. Como afirmam Palmieri e Cury (2007), a base teórica do plantão psicológico no contexto brasileiro foi a humanista, sendo que a proposta de referência foi a do Serviço de aconselhamento psicológico da Universidade de São Paulo (SAP-USP). Ao longo dos anos e dos diversos estudos realizados, a abordagem humanista foi cedendo espaço à fenomenológico-existencial no LEFE e no SAP, de modo que essa tendência foi acompanhada nas pesquisas desenvolvidas na pós-graduação do Instituto de Psicologia da USP, notadamente no Programa de Psicologia Escolar e do Desenvolvimento Humano.

Essa característica, embora fortaleça a construção de conhecimentos na interface entre o plantão psicológico e abordagem fenomenológico-existencial, uma referência no contexto nacional, deflagra que poucas são as pesquisas e intervenções desenvolvidas em outras abordagens, como a Psicologia Positiva (corrente contemporânea inspirada nos estudos de Rogers e Maslow), a psicanálise (Peres, Santos, \& Coelho, 2004) ou a cognitivo-comportamental (Lessard, Marchand, Lovoie, \& 2012). Incentivar o desenvolvimento do plantão psicológico em outras perspectivas pode ser um movimento importante no sentido de trazer à baila não apenas outras compreensões do que vem a ser o atendimento psicológico na urgência, mas também de estratégias e recursos que podem ser utilizados para o acolhimento e para o bem-estar psicológico daquele que busca ajuda. O foco nos aspectos positivos do cliente e na potencialização de seus recursos e de sua resiliência, como afirmado pela Psicologia Positiva (Scorsolini-Comin, 2014c), encontra um diálogo profícuo com a abordagem humanista, o que pode deflagrar estudos nesse campo de intersecção. O diálogo entre essas e outras abordagens faz-se necessário, assim como a divulgação de iniciativas desenvolvidas em outros contextos, como o internacional, como destacado a seguir.

\section{Diálogo com a produção internacional}

A análise da produção internacional na área, recuperada, em sua maioria, pela busca na base PsycINFO, destacou cinco registros em língua portuguesa, sendo um desses artigos desenvolvido por autora brasileira no exterior (Weintraub, 2011). Os demais são artigos oriundos dos Estados Unidos $(n=3)$ e Canadá $(n=1)$. Os estudos tratam de intervenções desenvolvidas em contextos de urgência e emergência, como em atentados terroristas, a exemplo do ocorrido em 11 de setembro de 2001 nos Estados Unidos (Carmona, 2007; Knotek, 2006) ou em guerras civis, como no Haiti e na República Democrática do Congo (Weintraub, 2011). Os programas desenvolvidos nos Estados Unidos e no Canadá e que não fazem referência aos autores presentes nas produções brasileiras destacam a necessidade de prevenção de danos às pessoas envolvidas em situações de ataques terroristas. A prevenção ao terror, intensificada após 2001, é acompanhada por iniciativas que visam a atender, prontamente, as pessoas afetadas e suas famílias. São mencionados diversos programas de acompanhamento e prevenção em escolas e universidades, de enfoque mais aproximado de abordagens psicométricas e cognitivo-comportamentais, em um aporte que pode ser considerado mais coletivo, de atenção à comunidade.

Isso pode evidenciar que o modelo de plantão psicológico, comumente desenvolvido no Brasil, distancia-se dos atendimentos psicológicos em situação de urgência observados no contexto internacional. A noção de urgência e emergência encontrada nos estudos internacionais aqui em destaque, também, traz à baila eventos coletivos de calamidade, diferentemente do que observa-se nacionalmente, em que predomina a menção à urgência psicológica relacionada a diversas demandas individuais. O pronto-atendimento realizado no exterior, desse modo, apresenta-se de maneira distinta do operacionalizado no Brasil, o que é clarificado nesta revisão.

Não se trata de dizer que não há atendimentos em plantão no exterior, mas essas intervenções 
apresentam-se de maneira distinta das que são veiculadas no cenário brasileiro, o que revela a flexibilidade do plantão para a atenção psicológica em cenários e condições diversas. Também não se pode afirmar que o plantão psicológico desenvolvido no Brasil alinha-se exclusivamente aos atendimentos individuais. Para exemplificar essa abertura, destaca-se o estudo de Coin-Carvalho e Ostronoff (2014), que narra o plantão comunitário realizado na modalidade grupal sob o enfoque da terapia comunitária. A interlocução entre a Psicologia clínica e as políticas públicas também vem sendo sublinhada como forma de promover uma escuta não apenas ligada a demandas individuais, mas que estabeleça interface com a comunidade e um campo mais amplo que o domínio psicológico (Vieira \& Boris, 2012). O plantão, desse modo, emerge como modalidade que estabelece esse necessário diálogo, o que destaca a atuação do profissional de Psicologia em uma perspectiva de clínica ampliada e consciente de sua implicação na comunidade de referência (Scorsolini-Comin, 2014a, 2014b).

A consideração dos diferentes contextos e culturas é fundamental nessa leitura da produção sobre o atendimento psicológico em situações de urgência e emergência, haja vista que as demandas apresentadas são bastante distintas, de modo que as abordagens e programas existentes são condizentes com as necessidades apresentadas em cada país. Uma importante consideração é trazida por Weintraub (2011) no contexto da ajuda humanitária oferecida no Haiti e na República Democrática do Congo. Comparando as duas realidades e as intervenções desenvolvidas em ambos os contextos, a autora destaca a importância de que os atendimentos psicológicos não se deem exclusivamente com base nos conhecimentos psicológicos, mas que a ajuda prestada possa ser oferecida em contato com outros profissionais, de diferentes disciplinas, a fim de que o psicólogo possa atuar de modo integrado à equipe e proporcionar um atendimento mais coerente com o contexto de atenção e com a situação de emergência que se apresenta. No Brasil, a menção clara a uma atuação multi ou interdisciplinar no plantão psicológico ainda é rara, mas vem norteando reflexões de diversos profissionais da Psicologia.

Assim, cabe ao psicólogo não apenas zelar pelo cuidado em situações de urgência e emergência, mas de fornecer informações necessárias à sobrevivência em cenários de guerra, terror e calamidade, ou seja, cabe a esse profissional apropriar-se do contexto de atuação para que possa promover um atendimento adequado às necessidades daqueles que buscam ajuda. A formação de profissionais de Psicologia no Brasil para a atuação nesses contextos de calamidade, ainda, é tímida, se comparada a outros países. As técnicas relatadas nos estudos internacionais tomam por base experiências fortemente estruturadas e organizadas, com alto nível de planejamento e foco na prevenção, notadamente no contexto norte-americano. Nos estudos internacionais, observa-se pouca menção ao referencial teórico empregado, não sendo exploradas discussões teóricas ou críticas acerca de abordagens utilizadas no pronto-atendimento psicológico.

\section{Considerações Finais}

As evidências disponíveis nos estudos recuperados mostram a contemporaneidade e a importância do campo do plantão psicológico como intervenção em situações de urgência e como prática de destaque na formação do psicólogo no contexto brasileiro. Ainda que as situações de emergência e urgência sejam diferentes das observadas nos contextos de outros países, o cenário brasileiro e a produção científica localizada nas universidades mostram a profusão de práticas de atendimento ao outro em situações de emergência e as vicissitudes desse processo.

O plantão psicológico é uma prática presente em diversas universidades, fomentado a partir da oferta de estágio curricular em cursos de Psicologia, em íntima relação com a extensão universitária à comunidade. Apesar da evidência de que essa prática é uma das mais frequentes em serviços-escolas de Psicologia, que lidam com a dificuldade de atender às demandas da população que busca ajuda desses profissionais, não são tão expressivos os relatos de investigações científicas conduzidas acerca do tema. O predomínio de relatos de experiência e pesquisas empíricas mostra a importância da prática na área, mas deflagra a necessidade de que o desenvolvimento dessas intervenções seja acompanhado e respaldado pelo conhecimento científico, pelo aprimoramento teórico, pelo diálogo entre abordagens e pela diversificação de enfoques e propostas de atendimentos. Um exemplo disso é o predomínio de uma única abordagem (fenomenológico-existencial) que, quando não assumida nos estudos, é apresentada como ponto de partida para outras propostas no aconselhamento e no plantão psicológico. Produzir práticas e pesquisas diversificadas implica em assumir a pluralidade que constitui o saber psicológico e a identidade do psicólogo. 
Entre as limitações deste estudo, destaca-se a utilização de apenas uma base digital de teses e dissertações, ligada a uma única universidade pública. Mesmo com essa limitação, a escolha dessa base corroborou a consideração de que se trata da instituição de ensino de onde provém a maioria dos estudos na área. Em futuras revisões, mostra-se importante a priorização do cenário da pós-graduação brasileira, a fim de compreender o real espaço ocupado pelas pesquisas sobre o plantão psicológico na atualidade. A exploração da literatura científica internacional pode ser realizada com a utilização de outras bases de dados, outros unitermos associados ou em periódicos específicos, a fim de resgatar práticas e pesquisas desenvolvidas em outros contextos e que, de fato, aproximem-se da prática de plantão desenvolvida em nosso país. Mesmo com tais limites, a presente revisão mostrou-se suficientemente ampla, a fim de incorporar evidências advindas de diferentes práticas e pesquisas sobre o cuidado na urgência, podendo ser considerada um retrato aproximado das intervenções realizadas na área e divulgadas em veículos de expressiva qualidade. Espera-se que a presente revisão contribua para que os profissionais que atuam no plantão psicológico possam incrementar suas práticas, em uma consideração positiva pela necessidade de desenvolvimento e veiculação de pesquisas que contribuam com esse fazer.

\section{Referências}

Amaral, A. E. V., Luca, L., Rodrigues, T. C., Leite, C. A, Lopes, F. L., \& Silva, M. A. (2012). Serviços de psicologia em clínicas-escola: Revisão de literatura. Boletim de Psicologia, 62(136), 37-52.

Aun, H. A., Morato, H. T. P., Noguchi, N. F. C., \& Nunes, A. P. (2006). Transgressão e juventude encarcerada: Outras versões a partir do plantão psicológico em unidades de internação da FEBEM/SP. Imaginário, 12(12), 35-53.

Bezerra, E. N. (2014). Plantão psicológico como modalidade de atendimento em psicologia escolar: Limites e possibilidades. Estudos e Pesquisas em Psicologia, 14(1), 129-143.

Braga, T. B. M., Mosqueira, S. M., \& Morato, H. T. P. (2012). Cartografia clínica em plantão psicológico: Investigação interventiva num projeto de atenção psicológica em distrito policial. Temas em Psicologia, 20(2), 555-570.
Campos, A. P. S., \& Cury, V. E. (2009). Atenção psicológica clínica: Encontros terapêuticos com crianças em uma creche. Paidéia (Ribeirão Preto), 19(42), 115-121.

Carmona, R. H. (2007). A key partner in the team: Psychology's role in emergency preparedness. Psychological Services, 4(2), 135-139.

Cautella Junior, W. (2012). Do inominável à pro-ducção de sentido: O plantão psicológico em hospital geral como utensílio para a metaforização da crise pelo trágico (Tese de Doutorado). Instituto de Psicologia, Universidade de São Paulo, São Paulo.

Chaves, P. B., \& Henriques, W. M. (2008). Plantão psicológico: De frente com o inesperado. Psicologia Argumento, 26(53), 151-157.

Coin-Carvalho, J. E., \& Ostronoff, V. H. (2014). Cuidado e transformação social: Avaliação da implantação do plantão comunitário no Complexo da Funerária. Estudos de Psicologia (Natal), 19(2), 89-156.

Doescher, A. M. L., \& Henriques, W. M. (2012). Plantão psicológico: Um encontro com o outro na urgência. Psicologia em Estudo, 17(4), 717-723.

Dutra, E. (2008). Afinal, o que significa o social nas práticas clínicas fenomenológico- existenciais? Estudos e Pesquisas em Psicologia, 8(2).

Furigo, R. C. P. L., Sampedro, K. M., Zanelato, L. S., Foloni, R. F., Ballalai, R. C., \& Ormrod, T. (2008). Plantão psicológico: Uma prática que se consolida. Boletim de Psicologia, 58(129), 185-192.

Gomes, F. M. D. (2008). Plantão psicológico: Novas possibilidades em saúde mental. Revista da SPAGESP, 9(1), 39-44.

Knotek, S. (2006). Administrative crisis consultation after 9/11: A university's systems response. Consulting Psychology Journal: Practice and Research, 58(3), 162-173.

Kovács, M. J. (2010). Sofrimento da equipe de saúde no contexto hospitalar: Cuidando do cuidador. Mundo Saúde, 34(4), 420-429.

Lessard, M-J, Marchand, A., \& Lavoie, K. L. (2012). Interventions à l'urgence pour douleurs thoraciques non cardiaques avec ou sans anxiété de type panique. Canadian Psychology, 53(3), 178-191.

Mahfoud, M. (Org.) (2012). Plantão psicológico: Novos horizontes. São Paulo: Companhia Ilimitada. 
Mahfoud, M. (2013). Desafios sempre renovados: Plantão psicológico. Em M. A. Tassinari, A. P. S. Cordeiro, \& W. T. Durange (Orgs.), Revisitando o plantão psicológico centrado na pessoa (pp. 33-50). Curitiba, PR: CRV.

Mendes, K. D. S., Silveira, R. C. C. P., \& Galvão, C. M. (2008). Revisão integrativa: método de pesquisa para a incorporação de evidências na saúde e na enfermagem. Texto \& Contexto Enfermagem, 17(4), 758-764.

Morato, H. T. P., Barreto, C. L. B. T., \& Nunes, A. P. (Orgs.) (2012), Aconselhamento psicológico numa perspectiva fenomenológica existencial: Uma introdução. Rio de Janeiro: Guanabara Koogan.

Mota, S. T., \& Goto, T. A. (2009). Plantão psicológico no CRAS em Poços de Caldas. Fractal, 21(3), 521-529.

Mozena, H. (2009). Plantão psicológico: Estudo fenomenológico em um serviço de assistência judiciária (Dissertação de Mestrado). Pontifícia Universidade Católica de Campinas, Campinas, SP.

Palmieri, T. H., \& Cury, V. E. (2007). Plantão psicológico em Hospital Geral: Um estudo fenomenológico. Psicologia: Reflexão e Crítica, 20(3), 472-479.

Paparelli, R. B., \& Nogueira-Martins, M. C. F. (2007). Psicólogos em formação: Vivências e demandas em plantão psicológico. Psicologia: Ciência e Profissão, 27(1), 64-79.

Perches, T. H. P., \& Cury, V. E. (2013). Plantão psicológico em hospital e o processo de mudança psicológica. Psicologia: Teoria e Pesquisa, 29(3), 313-320.

Peres, R. S., Santos, M. A., \& Coelho, H. M. B. (2004). Perfil da clientela de um programa de pronto-atendimento psicológico a estudantes universitários. Psicologia em Estudo, 9(1), 47-54.

Rebouças, M. S. S., \& Dutra, E. (2010). Plantão psicológico: Uma prática clínica da contemporaneidade. Revista da Abordagem Gestáltica, 16(1), 19-28.

Rocha, M. C. (2006). Juventude: Apostando no presente. Imaginário, 12(12), 205-223.

Rosenberg, R. L. (1987). Introdução: Biografia de um serviço. Em R. L. Rosenberg (Org.), Aconselhamento psicológico centrado na pessoa. São Paulo: EPU.
Scorsolini-Comin, F. (2014a). Plantão psicológico centrado na pessoa: Intervenção etnopsicológica em terreiro de umbanda. Temas em Psicologia, 22(4), 885-899.

Scorsolini-Comin, F. (2014b). Atenção psicológica e umbanda: Experiência de cuidado e acolhimento em saúde mental. Estudos e Pesquisas em Psicologia, 14(3), 773-794.

Scorsolini-Comin, F. (2014c). Aconselhamento psicológico com casais: Interlocuções entre psicologia positiva e abordagem centrada na pessoa. Contextos Clínicos, 7(2), 192-206.

Scorsolini-Comin, F, Souza, L. V., \& Santos, M. A. (2008). Tornar-se psicólogo: Experiência de estágio de Psico-oncologia em equipe multiprofissional de saúde. Revista Brasileira de Orientação Profissional, 9(2), p. 113-125.

Souza, B. N., \& Souza, A. M. (2011). Plantão psicológico no Brasil (1997-2009): Saberes e práticas compartilhados. Estudos de Psicologia (Campinas), 28(2), 241-249.

Schmidt, M. L. S. (2012). O nome, a taxonomia e o campo do aconselhamento psicológico. Em $\mathrm{H}$. T. P. Morato, C. L. B. T. Barreto, \& A. P. Nunes (Orgs.), Aconselhamento psicológico numa perspectiva fenomenológica existencial (pp. 1-21). Rio de Janeiro: Guanabara Koogan.

Tassinari, M. A. (2003). A clínica da urgência psicológica: Contribuiçoes da abordagem centrada na pessoa e da teoria do caos (Tese de Doutorado_. Universidade Federal do Rio de Janeiro, Rio de Janeiro.

Tassinari, M. A., Cordeiro, A. P. S., \& Durange, W. T. (Orgs.) (2013). Revisitando o plantão psicológico centrado na pessoa. Curitiba: CRV.

Vieira, E. M., \& Boris, G. D. J. B. (2012). O plantão psicológico como possibilidade de interlocução da psicologia clínica com as políticas públicas. Estudos e Pesquisas em Psicologia, 12(3), 883-896.

Weintraub, A. C. A. M. (2011). Psychological work in humanitarian emergencies in Haiti and Democratic Republic of Congo: Some considerations based on two work experiences. Saúde e Sociedade, 20(3), 811-820.

Recebido em: 07/01/2014

Reformulação em: 10/12/2014

Aprovado em: 22/12/2014 
Sobre o autor:

Fabio Scorsolini-Comin é professor adjunto do Departamento de Psicologia da Universidade Federal do Triângulo Mineiro e doutor em Psicologia pela Universidade de São Paulo.

\section{Contato com o autor:}

Departamento de Psicologia, Universidade Federal do Triângulo Mineiro Avenida Getúlio Guaritá, 159, Abadia, Uberaba, MG.

CEP: 38025-440

E-mail: fabioscorsolini@gmail.com

Psico-USF, Bragança Paulista, v. 20, n. 1, p. 163-173, jan./abr. 2015 